\title{
The Path of Shaanxi Agricultural Products Going out under the Belt and Road Initiative
}

\author{
Xiaoyan Zhou \\ Xi'an International University, Xi'an, 710077, China
}

Keywords: Shaanxi agricultural products; "One Belt, One Road"; development

Abstract: The "Belt and Road" Initiative is an important period of opportunity for Shaanxi agricultural products to go out. After years of development, Shaanxi's agricultural products "going out" has achieved initial results, but there are also some problems. This paper briefly introduces the status quo of Shaanxi agricultural products integration into the "Belt and Road" construction, analyzes the problems existing in Shaanxi's agricultural participation in the "Belt and Road" construction, and mainly expounds the path choice of Shaanxi agriculture to participate in the "Belt and Road" construction, in order to develop economy in shaanxi province, enhance the competitiveness of Shaanxi agricultural products industry and provide consumers with better quality agricultural products.

\section{Introduction}

When General Secretary Xi Jinping came to Shaanxi to inspect, he emphasized that Shaanxi should find a correct position and actively integrate into the "One Belt, One Road" pattern, and put forward the goal and expectation of "catching over and surpassing" in Shaanxi, pointing out that "it is necessary to base on the diversity of resources and solidly promote the modernization of agriculture". As a major agricultural province, Shaanxi has a unique geographical location and complex topography, which has spawned a variety of species resources, such as apples, kiwis, konjac, red dates, mung beans, and buckwheat, all of which are agricultural products that develop an export-oriented economy. The agricultural products of Shaanxi Province are actively integrated into the "One Belt and One Road" construction, and the global agricultural resource allocation and competition are an effective way to further promote the reform of Shaanxi agricultural supply side and promote the transformation of agricultural industrial structure and development mode ${ }^{[1]}$.

\section{The status quo of the integration of Shaanxi agricultural products into the "Belt and Road"}

As far as the current development status of Shaanxi's agricultural integration into the "Belt and Road" construction is in the stage of catching up and surpassing, Shaanxi Province, as the main node of the Belt and Road Initiative, will be guided by the construction of a new highland for inland reform and opening up. Efforts to build a preferred place to undertake industrial transfer from the east to the world, to establish transportation outside the maritime silk, and to develop and introduce a series of plans and measures. With the fruitful exchanges and cooperation in the economy, science and technology, and culture in the countries and regions along the Silk Road, we can lay a solid 
foundation for the development of the "Belt and Road" construction.

At present, Shaanxi is the province's force. It is integrating the resources of agriculture to participate in the "Belt and Road" construction, actively declares the free trade pilot zone of the Silk Road Economic Belt, and strives to build a new highland that can better drive external development. In the process of agricultural participation in the "Belt and Road" construction, we must take technology as the core, the corresponding capital as the link, the agricultural planting and processing enterprises as the mainstay, and market-oriented, gradually build state-funded innovation demonstration zones and national comprehensive innovation reforms. In the pilot area, accelerate the financial reform and innovation of Shaanxi Province, and strive to build an influential financial center on the Silk Road Economic Belt ${ }^{[2]}$.

\section{Problems in Shaanxi's participation in the construction of the "Belt and Road"}

\subsection{Agricultural product logistics management mode and technology backward}

The agricultural product logistics in Shaanxi Province started relatively late in the eastern region, and its development is relatively backward, mainly reflected in the technical level and management mode. The modern logistics industry is reflected in the operation and subsequent complementary services to the products. In addition, at present, Shaanxi Province has not yet formed a complete cold chain logistics system for agricultural products, or it is still in a traditional normal temperature logistics mode. The phenomenon of agricultural product decay and deterioration during transportation has extensively affected the economic benefits of Shaanxi agricultural products.

\subsection{Agricultural cooperation and exchanges are not deep}

Insufficient agricultural cooperation and exchange is the main factor restricting the participation of Shaanxi agricultural products in the construction of "One Belt and One Road". It is a multi-level and multi-form international in the fields of introduction of provenance, agricultural facilities and equipment, agricultural innovation and technology exchange, talent training, and deep processing of agricultural products. Exchanges and cooperation in exchanges and cooperation are not deep enough. It has been difficult to make major breakthroughs in the production, variety and quality of Shaanxi agricultural products ${ }^{[3]}$.

\subsection{The guarantee mechanism is not sound enough}

Improving the construction of the guarantee mechanism is the key and prerequisite for the agricultural participation in the "Belt and Road" construction, and is also the basis for ensuring the smooth implementation of related work. However, as far as the current status of agricultural development in Shaanxi is concerned, various safeguard mechanisms are still not perfect, which limits the efficiency of Shaanxi's participation in the construction of the "Belt and Road" to a certain extent.

4. The Path choice of Shaanxi agriculture participating in the construction of "Belt and Road"

\subsection{Give full play to natural advantages and develop high-end agricultural products}

Shaanxi has rich agricultural resources and actively develops green and organic high-end agricultural products. Focus on creating kiwifruit and apple brands as shown in Figure 1. Relying 
on the Northwest A\&F University and agricultural research units, we will continue to innovate in the entire supply chain of agricultural products breeding, planting, pest control, deep processing, preservation, transportation and sales, and build Internet+ agricultural products. The logistics information platform, expand sales channels, establish Shaanxi agricultural product brands, so that Shaanxi agricultural products have a certain influence in the international market.

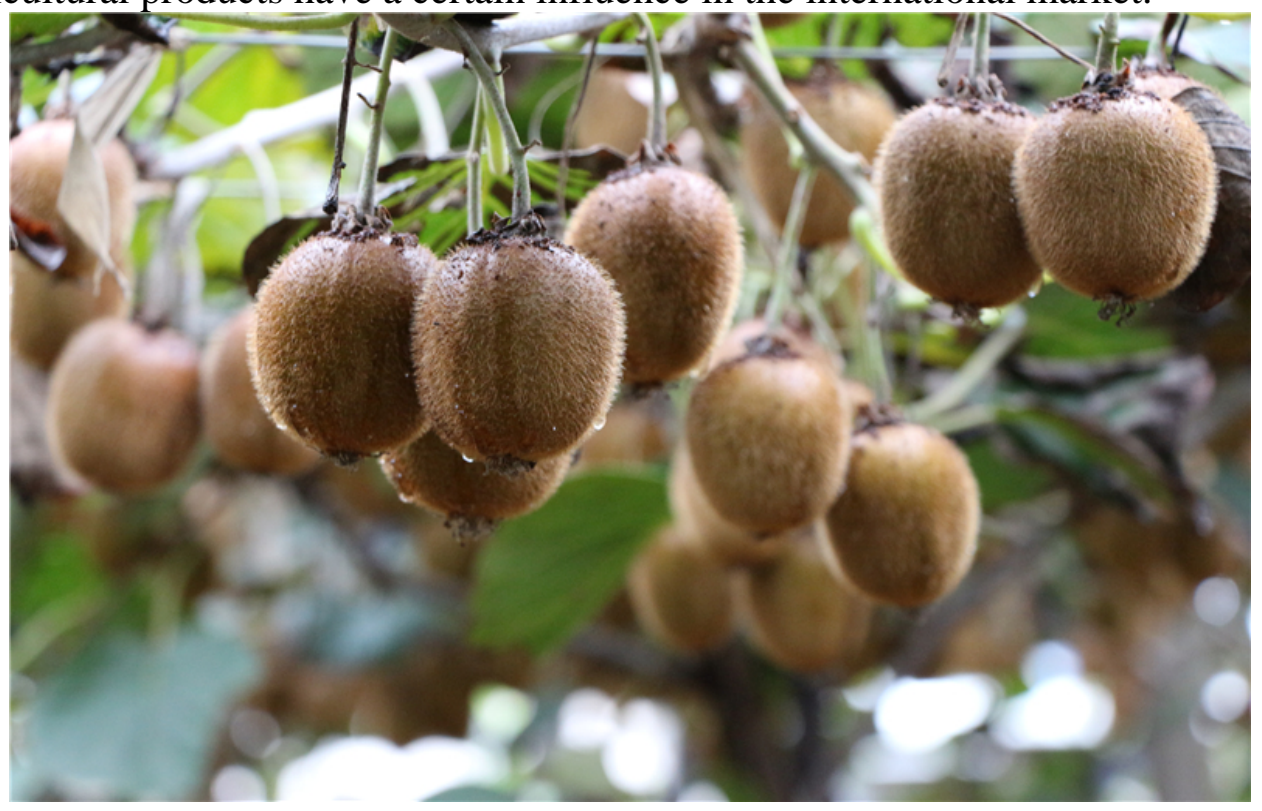

Figure 1 Famous kiwifruit base in Shaanxi Province

\subsection{Increase infrastructure construction and promote the development of agricultural products logistics}

The most fundamental measure for developing agricultural product logistics is to build a developed transportation network. With the implementation of the "One Belt, One Road" initiative, the first is to build infrastructure in the cities and regions along the "Belt and Road". Many enterprises have already invested in the foundation. The construction of the facility comes. Shaanxi Province should take advantage of this opportunity to coordinate the infrastructure construction with the agricultural product logistics industry, and interconnect the remote areas with the cities along the "Belt and Road" to enable all agricultural production sites to connect to the "Belt and Road" traffic artery.

Shaanxi Province should increase investment in agricultural product logistics industry and promote the research and development of cold chain facilities and equipment for agricultural products. At the same time, it is necessary to improve the rural environment and attract talents from agricultural products logistics to "walk in and stay" through the tilt of talent policies. Finally, formulate policies in taxation to attract high-quality agricultural products logistics companies from other regions to invest in Shaanxi to help local enterprises grow ${ }^{[4]}$.

\subsection{Accelerate the construction of cooperative parks and develop the group}

Under the trend of "One Belt, One Road" and global economic integration, if Shaanxi wants to give full play to the advantages of the origin of the Silk Road, it is necessary to speed up the construction of the cooperative park and maximize the level of Shaanxi's opening to the outside world. First, gradually adapt to the development trend of regional economic integration of domestic enterprises, and gradually open up Shaanxi's import and export from the Yangtze River Basin and 
the eastern coastal economic belt, and seize the opportunity to build a national new district in Xixian. Second, take the initiative to learn from the experience and enlightenment of agricultural cooperation and exchange in the Shanghai Free Trade Zone. Third, gradually expand the channels for economic and trade exchanges and give full play to the role and platform of the "Belt and Road". Table 1 shows the development of economy and foreign trade in Shaanxi Province under the "One Belt, One Road" strategy in recent years.

Table 1 The effect of Shaanxi agriculture participating in the construction of "Belt and Road"

\begin{tabular}{|l|l|l|l|l|}
\hline Years & $\begin{array}{l}\text { GDP } \\
\text { ranking }\end{array}$ & $\begin{array}{l}\text { Economic } \\
\text { growth rate }\end{array}$ & $\begin{array}{l}\text { Import and } \\
\text { export } \\
\left(100 \quad \begin{array}{r}\text { Import alue } \\
\text { million }\end{array}\right.\end{array}$ & $\begin{array}{l}\text { and } \\
\text { export increased } \\
\text { compared with } \\
2012(\%)\end{array}$ \\
\hline 2013 & 16 & $7.9 \%$ & 1246.62 & 33.45 \\
\hline 2014 & 16 & $9.7 \%$ & 1680.72 & 79.92 \\
\hline 2015 & 15 & $11.0 \%$ & 1895.40 & 102.90 \\
\hline
\end{tabular}

\subsection{Improve the public service system and strengthen environmental protection}

Service is productivity. First, we must build an information service platform, comprehensively collect, organize, analyze and publish the "Belt and Road" agricultural product trade information, explore the establishment of a stable foreign agricultural investment cooperation information collection network, realize resource sharing, information interaction, and organize on the basis of information sharing. Experts conduct analysis. The second is to establish and improve an intermediary service network for agricultural products. Make full use of the intermediary service organizations established by overseas Chinese and overseas Chinese to provide investment environment assessment, legal and project consulting services for overseas agriculture-related enterprises $^{[5]}$.

\section{Conclusions}

Under the background of the "Belt and Road Initiative", the development of agricultural products in Shaanxi Province has ushered in a major opportunity. Shaanxi province needs to take the development perspective and seize the current opportunity to build its own brand, speed up infrastructure construction, develop agricultural products logistics, speed up the construction of cooperative parks, and improve the public service system. Only by improving the logistics technology, operation level and service quality of Shaanxi's agricultural products can Shaanxi provide better agricultural products to the world, drive trade along the silk road, further promote the implementation of the "One Belt And One Road" initiative, and reproduce the glorious history of the ancient silk road of Shaanxi province.

\section{Acknowledgement}

The trade on export of agricultural products between Shaanxi and Countries along The Belt and Road on the view of supply-side reform, $2018 \mathrm{C} 004$.

\section{References}

[1] Wang Hongyan, Wang Xiaowei. Analysis of Shaanxi Agricultural Product Logistics Development under the "Belt and Road Initiative"[J]. Liaoning Agricultural Sciences, 2018(2).

[2] Wang Ying. On the New Opportunities Brought by the "One Belt, One Road" Initiative to Shaanxi Enterprises to Go 
Global [J]. Knowledge Economy, 2017(22): 7-8.

[3] Guo Jingli, Sheng Caijiao, Li Sijing. Policy Thinking on the "One Belt, One Road" Agricultural Science and Technology Going Out[J]. China Agricultural Science and Technology Review, 2017, 19(11): 1-7.

[4] Du Lingyan. Research on the Development of China's Agricultural Products Trade under the "Belt and Road Initiative” [J]. Modern Marketing (late issue), 2018(5).

[5] Zheng Guofu. Research on Optimizing the Development Path of Sino-Vietnamese Agricultural Trade Cooperation under the "Belt and Road Initiative"[J]. Price Monthly, 2018(2). 